International Review of Research in Open and Distributed Learning Volume 16, Number 2

April - 2015

\title{
Online Text Processing: A Study of Iranian EFL Learners' Vocabulary Knowledge
}

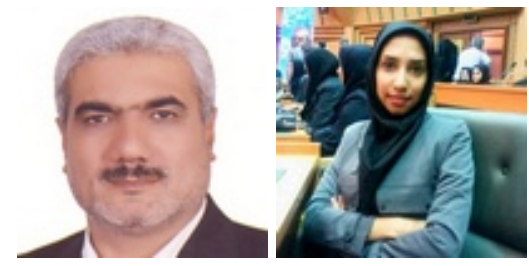

Abbas Ali Ahangar and Mehri Izadi

\begin{abstract}
The internet has developed into an important source of knowledge in recent times. It is used not just for engaging and entertaining users, but also for promoting language learning, especially for English as a Second/Foreign Language (ESL and EFL) learners spending long hours using internet, 85\% of all web pages are in English. This experimental research investigated EFL learners' experiences of vocabulary learning while surfing and text processing. In this small-scale study, two homogeneous groups of EFL learners $(\mathrm{N}=19)$, after taking a vocabulary test to ensure that their vocabulary knowledge differences were not significant, were randomly assigned to attend Interchange 3 class in two different groups - one as the Experimental and the other as the Control Group. Each session, there was a free discussion on special topics; while the Experimental Group surfed the internet, processed the online texts, shared and discussed their findings and beliefs on the internet, the Control Group did not use the internet and simply shared their opinions and discussed their personal beliefs. The results of the vocabulary pre- and post-tests indicated that the "internet users" significantly outperformed the "non-internet users", that is, the Control Group. Based on the findings, internet creates a stimulating environment which helps learners effectively boost their vocabulary knowledge.
\end{abstract}

Keywords: Internet; text processing; vocabulary learning; open and distance learning

* Corresponding author, PHD Candidate in TEFL 


\section{Introduction}

The internet was a creation of far-fetched technological inventions during 1950s which altered human communication like nothing before. It is at once a world-wide broadcasting capability that dominates all sides of the educational, business, and economic spheres of our world (Singhal, 1997). Pervasive in numerous fields and domains, internet, unquestionably, "carries great potential for educational use, specifically second and foreign language education" (Singhal, 1997, p. 107). The internet provides learners with valuable language resources and makes them capable to communicate openly with native speakers (Kost, 1999; Kroonenberg, 1994). Today's students are encouraged to use internet to look up information for doing projects, preparing and presenting talks and communicating (Cox et al., 2004; Somekh et al., 2002). This, as a result, has given rise to more openness in educational practices and made learners less constrained by boundaries that otherwise impede instruction and learning as physical presence in class. Therefore, open educational practices (OEP) enable teachers to connect with their learners with greater ease, at a larger scale and on a continuing basis (Schreurs, Van den Beemt, Prinsen, Witthaus, Conole, \& De Laat, 2014). It is no doubt that English language dominates this networkbased learning; more than half of the home pages are in English (Crystal, 1997c, 2001). As a consequence, internet use results in many facets of language development, inasmuch as learners surfing the primarily text-based internet read and write in English, which helps them acquire the language (Mike, 1996). Internet creates huge opportunities for the expansion and enrichment of language.

Therefore, it is worthwhile to study the impact of the unmoderated use of the internet on the learners' language development. The present study investigates the effect of internet surfing and online text processing on EFL learners' vocabulary knowledge. The results are helpful for both teachers and students to embrace OEP in order to improve language teaching methods at all levels of education, especially vocabulary knowledge.

\section{Internet and Foreign Language Learning}

The prevalence of the internet makes it more and more important to know how to use internet resources and services and, as a part of this, to read and write in English. The role of the internet in language learning is continuing to grow as it provides students with interactive learning resources (Cox et al., 2004; Crystal, 2001; Somekh et al., 2002). When one is familiar with some English, s/ he can expand it just by applying it on the internet. According to Mike (1996), internet improves learners' thinking skills. As students search for specific information, they must inspect various resources and texts which entail scanning, discarding, and evaluative judgments. Following that, learners are required "to make a complete and coherent whole which entails the synthesis process" (Singhal, 1997, p. 107). This interacting with internet, accordingly, develops their reading skills and strategies and improves their lexicon (Mahmoudi \& Razak, 2012; Shams, 2013). Moreover, learners can both read and use information on the internet and actually generate and present their own works such as essays, reports, or stories, as well. Learners are also

This work is licensed under a Creative Commons Attribution 4.0 International License. 
contextualized and experience the real world when they are exploring the internet and communicating with native speakers (Crystal, 2001). This internet mediated learning, then, serves as a medium which helps and facilitates open and distance learning (ODL). It provides many-to-many communication, synchronous tasks, and time- and place-independent learning; each contributes to flourishing learners' language competence (Najafi, Evans, \& Federico, 2014, Velasquez, Graham, \& West, 2013). It enables teachers and learners from far-flung areas to establish connections and engage in activities using L2, target language. Instructors, thus, can serve as mentors to assist learners to correspond asynchronously or in real time to investigate and study specific topics individually or in an interactive format. ODL seizes the opportunity to develop, distribute and apply knowledge more promptly and productively.

\section{Vocabulary Learning}

Vocabulary language teaching is often a neglected area (Morgan, Rinvolucri, \& Maley, 1986). New items are presented in long lists with their translation or presented as they appeared in reading or listening texts. "The word vocabulary has long connoted word lists, and vocabulary learning strategies have been considered techniques that help commit these lists to memory" (Gu \& Johnson 1996, p. 643). According to Meara (1980) "these laboratory experiments completely ignore the complex patterns of meaning relationships that characterize a proper, fully formed lexicon" (p. 225). As a result, vocabulary learning is often perceived as boring by learners. On the other hand, without a large vocabulary base, it is difficult to hold a proper conversation. Turgut and Irgin (2009) asserted that "the internet has opened up a world of possibilities for improving the vocabularies of learners (p. 761). ODL (e.g., online games and programs) assists students to start an adventure of reading and writing and become autonomous learners. In this way, vocabulary learning shifts to pleasurable learning (Turgut \& Irgin, 2009; Mahmoudi \& Razak, 2012; Shams, 2013). Online texts play a large role in establishing how words are actually used in speech and writing (Mustafa, Sain \& Razak, 2012; Naraghizadeh \& Barimani, 2013). In other words, internet resources and online texts stimulate deeper processing of words. It contextualizes vocabularies; since semantic related items are grouped together in the mental lexicon, it is useful to organize vocabularies in semantic fields, such as in topics (Gass \& Selinker, 2008). Moreover, if words are learned in context instead of in random lists they are more likely to be remembered in the long term. It is also worth mentioning that frequently used items are easier to retrieve (Honeyfield, 1977). In terms of OEP, teachers can present learners with contextualized vocabularies on which learners can continuously work, receive feedback and remember items more swiftly.

Generally speaking, the OEP expands the possibilities for teaching and learning. Thereafter, it must be realized that the ODL's, particularly internet, educational potential is immense. Teachers and learners must apply the internet and its various functions. They must also use specific search resources in order to access information, search for lesson plans, or materials and ideas that, as a result, can greatly enhance the language learning experience.

This work is licensed under a Creative Commons Attribution 4.0 International License. 


\section{Literature Review}

ODL has revealed promise in addressing a number of concerns raised in F/S language teaching and learning. Studies have shown that internet-mediated language learning improves writing skill and thinking connection (Al-J arf, 2004; Warschauer, 1995), develops communication and oral discussion, reduces anxiety (Blasszauer, 2001; Weininger \& Shield, 2003), nurtures cooperative learning, enhances student motivation, and facilitates cross-cultural awareness (Brandl, 2002; J ogan, Ana, \& Gladys, 2001; Meskill \& Anthony, 2005; Yang, 2001). In their studies, Hertel (2003), Leloup (1997) and Warschauer (1995) showed that e-mail based activities improve writing skills. E-mail and chat, reported Kost (1999), Hellebrandt (1999) and Kroonenberg (1994), enhance communicative language skills, social learning and critical thinking skills. Chat, for example, "cultivates the ability to think and compose spontaneously" (Kroonenberg, 1994, p. 26). Researchers also reported that e-mail improved reading comprehension (Lunde, 1990) and increased speaking self-confidence (Beauvois, 1994). Yang and Chen (2007) asserted that "the conversational aspect of writing via the network may have helped students to routinize certain expressions, thus promoting the development of automatic structures that assists speaking" ( $\mathrm{p}$. 863). In another study, in comparison with traditional teaching method, Facebook as course webpage revealed intensive collaboration and active learning which stimulated a dynamic learning environment (Meishar-Tal, Kurtz, Pieterse, 2012).

According to Liu (1995) and Hult, Kalaja, Lassila, and Lehtisalo (1990), hypermedia technology enhances vocabulary learning and reading comprehension. In studying web-based learning, Braine and Yorozu (1998), Cononelos and Oliva (1993) and Hartman et al. (1991) reported that students participated and discussed more during interaction hence their confidence and feedback gradually increased. Chalmers (2003) also claimed that the WebQuest serves to organize the learning process and help learners to be autonomous. Segers and Verhoeven (2009) investigated the effects of using WebQuests in elementary school classrooms in the Netherlands. 229 sixth grade students participated in either a free-search Google condition or a closed-search WebQuest condition. Results showed that children's information processing and linguistic skills generally influenced their learning effectiveness and did not interact with condition. Free-search condition revealed the highest improvement in students' writing, and close-searched condition showed the highest learning effectiveness for boys. The analysis of peer feedback in online project-based learning also delineated supportive collaboration between peers as they frequently provided constructive assistance to advance their pairs' thinking (Ching \& Hsu, 2013). Working with postgraduate learners, J owallah (2014) explored synchronous and asynchronous learning and the effect of web conferencing on planning one-on-one meetings and research seminars. Findings of the study indicated that applied strategies helped learners build confidence and manage their work effectively, improve their learning experience, promote intellectual learning, receive feedback and assess their progress.

Concerning studies performed on ODL in Iran, Zarei and Khazaie (2011) explored the ease of recognition and recall of vocabulary items through using laptop. New vocabularies were presented 
to learners through two modes of visual and verbal and at two high and low levels of ability. The analysis of findings revealed that the programed software provided through laptop enhances the recognition and retrieval of vocabularies. In another study, Shams (2013) explored Iranian learners' autonomy and vocabulary improvement while attending a hybrid vocabulary course. The researcher taught selected words in groups and asked learners to publish posts and reflective essays in the assigned weblog on a regular basis. The findings of the study revealed that learners' autonomy increased and their knowledge of vocabularies was boosted. The study stressed the importance of implementing computer- and self-assisted learning by the help of technological aids. Other studies with similar context, Agca and Ozdemir (2013) in Turkey, Mahoudi, Samad, and Razak (2012) and Mustafa et al. (2012) in Malaysia, explored the effect of mobile, computer and internet on learners' vocabulary learning, respectively. The studies argued that ODL delineated tremendous increase in learners' performances, particularly vocabulary. According to these studies, this new method of teaching and learning can optimize learning effectiveness. In spite of its promising results, ODL has only recently been introduced in Iran; however, there is a growing interest in implementing ODL and OEP in language education especially higher education. The mother tongue and primary language of Iran is Persian/Farsi and English is taught as L2 from guidance school. English language education is regarded as important inasmuch as it is being employed largely in academic, economic and other aspects of life. The great advantages in personalizing and contextualizing learning processes over ODL in other countries have brought to eyes the importance of applying this support-driven technique in education in Iran. The findings of this and forthcoming studies, as a consequence, can help the flourishing of ODL in context of Iran.

Upon the importance of vocabulary in language learning and the necessity of helping learners to acquire vocabularies more promptly, therefore, new teaching methods and instruments are required for learners in this era of information and communication technology to initiate vocabularies. As it is established in the literature, F/ S language learners are ceaselessly in need of not only developing but updating their knowledge of words. Vocabulary learning is not the matter of memorizing a list of selected words but it has been shown to require deeper processing of meaning. Technological breakthrough, particularly internet and in turn ODL, has introduced a novel route to contrive a better educational environment. Unsatisfactory outcomes of existing vocabulary teaching methods have, further, made instructors and learners excited to embrace this rich learning environment grounded in (online) networks of ODL. In this respect, the present study investigated how this delivery mode of education and instruction influences the learning of practitioners. The results of the study lead to practical implications on how to sustain participation and prosper learning in ODL.

In line with the objective of the study, the researchers have attempted to investigate the following question:

Does the use of online texts by Iranian EFL learners bring about any variation in their vocabulary knowledge?

This work is licensed under a Creative Commons Attribution 4.0 International License. 
On the basis of the above research question, the following null hypothesis may be formulated. Hence, the statistical results of the study would either support or reject the null hypothesis:

$\mathrm{H}_{0}$ :The use of online texts by Iranian EFL learners has no effect on their vocabulary improvement.

\section{Methodology}

\section{Participants}

This study was conducted in the context of a university discussion course at Chabahar public university from April 2014 to June 2014. Random sampling method was used to select participants.

A simple random sample is one in which each and every member of the population has an equal and independent chance of being selected, and it is the best way yet devised to obtain a sample representative of the population of interest. (Fraenkel, Wallen \& Hyun, 2011, p. 94)

Out of the enrolled students for this course, 20 undergraduate EFL learners majoring in English language and literature were selected. One learner, however, was dropped from the study due to missing data. Learners aged from 19 to 21 years old with the mean of 20 of both males $(\mathrm{N}=11)$ and females $(\mathrm{N}=8)$. As sophomore students, learners have studied English language for two years and were at the intermediate level of proficiency based on their scores on previous term. All learners were from similar social class and had no experience of ODL. An experienced instructor, who is the researcher of the study as well, taught learners.

To be assured of learners' homogeneity in vocabulary knowledge, the participant learners took a Vocabulary Level Test (VLT) designed by Nation and Beglar (2007). They were then randomly assigned to attend Interchange 3 part 2 classes in two groups: Experimental and Control Groups. To have reliable data, Experimental learners were also taught on internet using and text processing in five extra sessions in two weeks before the study. After the instruction, the instructor tested learners on proficiency in using internet and learners revealed similar capability in internet surfing.

\section{Materials}

Two tests were used as instruments in the study. In order to see whether the students were of the same level of vocabulary knowledge, VLT designed by Nation and Beglar (2007), including 140

This work is licensed under a Creative Commons Attribution 4.0 International License. 
multiple-choice questions, was given to the students. The first test was administrated among the students before dividing them into two groups.

The second instrument of the study was a 60 multiple-choice vocabulary test adopted from Essential Words for the TOEFL (Matthiesen, 2007). The second test was used twice, once as a pre-test at the beginning of the term and once as a post-test at the end of the semester. The test was employed to examine differences between two groups in their knowledge of words in English before and after intervention.

As a part of the course materials, the second four units of Interchange 3 were selected to work on with students in twenty sessions. Each unit had a general topic and some subtopics:

Unit 1: Crossing Cultures, Cultural Comparisons and Culture Shock, Moving Abroad, Cultural Expectation, Emotions, Customs, Tourism and Travel Abroad, Advices and Suggestions.

Unit 2: Everyday Problems, Consumer Complaints, Making Complaints, Common Complaints in Different Situations, Customer Rights, After-Sale Services, Guilds, Common Market Products, Advices and Suggestions.

Unit 3: The World We Live in, The Environment, World Problem, Government Programs, Global Warming, Current Issues, Trash and Recycling, Air Pollution, Growth of Suburb, Environmental Protection Agency, Industrial Waste, Advices and Suggestions.

Unit 4: Lifelong Learning, Education, Learner Choices, Preferences, Strategies for Learning, Personal Qualities, Learner Styles, Pros and Cons of Different College Majors, Popular College Majors, Education System in Iran, Public and Private Universities, Learning Methods, Advices and Suggestions.

Moreover, six websites were introduced to the Experimental Group as part of their resources for surfing and text processing:

www.wikipedia.com

www.reference.com

www.infoplease.com

www.britannica.com 
www.thefreedictionary.com

www.nationmaster.com

\section{Procedure}

The present study adopted experimental research method with pre-test-treatment-post-test design. After randomly assigning participants to two groups (Experimental Group: 9 and Control Group: 10 students), the time of the class was divided to two equal sessions, the first 45 minute students were provided with conventional means of teaching each lesson by the instructor and the second 45 minute subjects participated in free discussion on topics and subtopics related to their units. While Control Group just expressed their opinions without being forced to explore the net and read online texts, Experimental Group was forced to surf and explore the suggested websites and the other websites they wanted, read different world views, think about them and, in the class, they clarified and defended their opinions based on whatever they found on the internet. Experimental group was asked, for example, to search in the online texts on "How to trust a product?", “What are after-sale services?" and "What are customer rights?”, read different texts and opinions, and the next session that they came to class they negotiated on what they found and what they thought and concluded. At the end of discussion, they were asked about the websites, texts and the writers that they read.

The Control Group, however, was not asked or was not encouraged to search in online texts. They were just asked to think about topics and subtopics and deliver their opinions. In other words, the Control Group was merely taught by applying the conventional procedures of teaching an English book and working on the exercise and texts of book and a free discussion.

Following the procedure, the data were collected for further analysis using Statistical Package for the Social Sciences (SPSS) 18. Descriptive statistics, independent and paired sample t-test were run to check the possible effect of text processing.

\section{Results and Discussion}

To have enough evidence on the participants' vocabulary knowledge, the researchers administrated VLT prior to the study. Findings of the test revealed that there were no statistically significant differences between the Experimental and Control Groups in their vocabulary knowledge, with results of $F=5.78, p=0.89>0.05$. Table 1 provides statistical results. 
Table 1

Vocabulary Size Test in the Experimental and Control Groups

\begin{tabular}{|c|c|c|c|c|c|c|}
\hline & \multirow{2}{*}{\multicolumn{2}{|c|}{$n=9^{\text {Experimental }}$}} & \multicolumn{3}{|c|}{ Control } & \multirow{3}{*}{$\mathrm{p}$} \\
\hline & & & $\mathrm{n}=10$ & & $\mathrm{t}$ & \\
\hline & $\bar{M}$ & SD & $\mathrm{M}$ & SD & & \\
\hline Vocabulary Size Test & 80.11 & 3.68 & 80.30 & 2.21 & -0.13 & 0.89 \\
\hline
\end{tabular}

In order to answer the research question, whether the use of online text by EFL learners brings about any variation in their vocabulary knowledge, the results of vocabulary pre- and post-tests from the Experimental and Control Groups were compared. It can be seen, therefore, that the use of online texts may represent a different learning environment as opposed to classroom learning where information usually flows unidirectionally - and generally from teachers to students.

Table 2 presents mean scores and standard deviations for the Experimental and Control Groups' vocabulary pre- and post-tests. In the pre-test, the Experimental Group and the Control Group, respectively, had $\mathrm{M}=25.00, \mathrm{SD}=3.24$, and $\mathrm{M}=25.80, \mathrm{SD}=2.09$. In the post-test, the Experimental Group and the Control Group, respectively, had $\mathrm{M}=32.88, \mathrm{SD}=1.90$, and $\mathrm{M}=26.90, \mathrm{SD}=2.13$. The results of Table 2 further indicate that there was no significant difference between the Experimental and Control Groups' mean scores on the pre-test $(t=-0.64, \mathrm{df}=17, \mathrm{p}=0.52>$ 0.05). The vocabulary knowledge of the Experimental Group is similar to that of the Control Group before the use of online text intervention started. However, there was a significant difference between the mean scores of the two groups on the post-test $(t=6.43, \mathrm{df}=17, \mathrm{p}=0.00$ $<0.05)$. The Experimental Group achieved significantly higher scores than the Control Group in the post-test. This means that after the use of online text intervention, the internet user group outperformed the Control Group on the vocabulary knowledge post-test. Assessing learners' improvement through computer-assisted language learning (CALL), Mustafa et al. (2012) asserted that "the increase marks for the Control Group is between 3 percent to 23 percent while the Experimental Group has an increase between 10 percent to 27 percent" (p. 427). Online vocabulary exercises have also shown the same development in learners' performances (Mahmoudi \& Razak, 2012). By the same token, Shams (2013) has depicted 83.33\% improvement in learners' vocabulary knowledge after exposing to a hybrid learning course. According to Shams, "attending this hybrid learning course proved effective for the initial participants of this study to develop their autonomy and vocabulary knowledge" (p. 1591). Similarly, experimental learners in this study could effectively fortify their vocabulary knowledge and apply them in discussion time. The high range of new vocabularies learners used in proving themselves or confirming their classmates was evidence of their vocabulary promotion.

This work is licensed under a Creative Commons Attribution 4.0 International License. 
Table 2

The Independent Samples T-Test for the Experimental and Control Groups

\begin{tabular}{|c|c|c|c|c|c|c|}
\hline & \multicolumn{2}{|c|}{$\begin{array}{c}\text { Experimental } \\
n=9\end{array}$} & \multicolumn{2}{|l|}{$\begin{array}{l}\text { Control } \\
n=10\end{array}$} & \multirow[t]{2}{*}{$\mathrm{t}$} & \multirow[t]{2}{*}{$\mathrm{p}$} \\
\hline & $\mathrm{M}$ & SD & $\mathrm{M}$ & SD & & \\
\hline Pre-test & $\overline{25.00}$ & 3.24 & 25.80 & 2.09 & -0.64 & 0.52 \\
\hline Post-test & 32.88 & 1.90 & 26.90 & 2.13 & 6.43 & 0.00 \\
\hline
\end{tabular}

$* \mathrm{p}<.05$

The results of paired t-tests in Table 3 also show that there was a significant difference between the Experimental Group's pre- and post-tests $(t=-7.88, \mathrm{df}=8, \mathrm{p}=0.00<0.05)$. That is, the participants who used internet, online texts, significantly improved their vocabulary knowledge. Internet helped learners not only develop their comprehension of words, absorb a large range of new vocabularies related to assigned topics, but also easily express their beliefs and discuss opinions. As shown in Table 3, there is no significant difference between the Control Group's preand post-tests $(\mathrm{t}=-1.10 \mathrm{df}=9, \mathrm{p}=0.10>0.05)$. That is, the participants who did not use internet and online texts did not significantly improve their vocabulary knowledge. By the same token, Al-Jarf (2004) argued that web-based writing significantly improved Experimental learners' post-test performances compared to their pre-test writings; "results of the paired t-test ... show a significant difference between the pre-test and post-test mean scores of the Experimental Group at the .01 level $(\mathrm{T}=12.14$, df=61)” (p. 9). Mahmoudi and Razak's (2012) findings "revealed that participants showed significant positive performance towards CALL $(\mathrm{M}=33.76, \mathrm{SD}=7.05, \mathrm{t}(29)=10.38, \mathrm{p}<0005)$... Therefore, the use of on-line instruction increased the range of respondent's English language vocabulary" (p. 496). Likewise, Naraghizadeh and Barimani (2013) reached significant differences of Experimental Group on their performance in pre-test and post-test $(t=43.64, p<0.01$ ) on effect of CALL instruction on learners' vocabulary development.

As it was mentioned, there were no significant differences in vocabulary knowledge between the groups at pre-test, while there were significant differences among them at post-test. Therefore, the differences may be attributed to the use or non-use of online texts by the participants. The obtained main scores by each of the two groups on the vocabulary post-test indicated that the Experimental Group obtained a higher mean than the Control Group, which turns out to be significant. By the $\mathrm{p} \leq \mathrm{0.05}$ ' we can reject the null hypothesis of the research, denoting that, using online texts would positively influence students' vocabulary learning, that is Experimental Group outperformed the Control Group. 
Table 3

Paired T-Test for Pre- and Post-Tests of the Experimental and Control Groups

\begin{tabular}{|c|c|c|c|c|c|c|}
\hline \multirow{2}{*}{ Paired Differences } & & & & & \multirow[b]{2}{*}{$\mathrm{df}$} & \multirow[b]{2}{*}{$p$} \\
\hline & $\mathrm{M}$ & SD & SEM & $\mathrm{t}$ & & \\
\hline $\begin{array}{l}\text { Experimental group } \\
\text { Pre-test -- Post-test }\end{array}$ & -7.88 & 1.61 & 0.53 & -14.64 & 8 & 0.00 \\
\hline $\begin{array}{l}\text { Control group } \\
\text { Pre-test-- Post-test }\end{array}$ & -1.10 & 0.73 & 0.23 & -0.71 & 9 & 0.10 \\
\hline
\end{tabular}

\section{Conclusion}

In the introduction, in line with object of the study, a research question was proposed: whether use of online texts by Iranian EFL learners brings about any variation in their vocabulary knowledge. Furthermore, on the basis of this research question, a null hypothesis was also proposed-assuming that the use of online texts by EFL learners has no effect on their vocabulary knowledge. The analysis of findings revealed that learners in Experimental Group significantly boosted their vocabulary knowledge compared to their counterparts in Control Group. It, accordingly, is concluded that learners who surfed the internet and read online texts performed better in their academic performances and thus the null hypothesis was rejected. Taking advantage of internet and therefore creating an ODL environment can be effective for other (Iranian) EFL learners with the same characteristics as the participants of this study.

According to the results, internet plays an important role in the learning process, specifically vocabulary. Online texts processing provides learners with contextualized vocabularies on various topics. Moreover, these natural repetitions in online texts allow language learners to be continuously exposed to the L2 and create more opportunities for acquisition to occur (Gass \& Selinker, 2008). In the other words, a kind of transmission of knowledge on the internet (online texts) occurs to solve the meaning of unknown words in the texts. As students visually see vocabulary and learn the meaning of words, they understand and retain them better and easier. Results obtained from pre- and post-tests also indicate that online texts have been perceived as having been stimulating and beneficial. Members of the Experimental Group expressed positive attitudes towards the use of online texts as a means of practicing their English at the end of the discussions; most of them spent considerably more time on the task than required and felt that their English improved as a result. For the participants, understanding the information presented in texts had importance, motivating them to learn unknown words and focusing on texts to catch the point.

This work is licensed under a Creative Commons Attribution 4.0 International License. 
Implications of the study signifies the value of development and evaluation that these open and distance type of learning and practices produce. Within this support-driven ODL network of practices, learners can learn from each other, share content, and self-instruct as the findings of the study contribute to flourishing outcomes, particularly vocabulary learning. ODL enables learners in dispersed geographical and organizational areas to have access to the needed external expertise and suggests more dynamic and useful learning practices. Instructors and curriculum developers can open up authentic communicative situations which encourage learners to engage, and afford their privacy while providing them with multi-retrieval cues, a learner-centered learning environment which shifts teachers' role from the sole knowledgeable person in class to an organizer and collaborator.

In sum, EFL learners using online texts as an OEP can promote their language learning and especially vocabulary skills. They would be best advised to try to use online texts that are useful resources for language learning. In relation to future English learning and technology, the study suggests ways forward in implementing the study and utilization of technology. Although preparing for an internet-based language lesson may be rather difficult, as far as browsing information on the net entails a substantial amount of time, it is undeniably pleasing employing it in learning process, as learners benefit from it immensely.

\section{Acknowledgment}

The authors would like to express their gratitude to the reviewers for their insightful comments. 


\section{References}

Al-J arf, R.S. (2004). The effects of web-based learning on struggling EFL college writers. Foreign Language Annals, 37(1), 49-57.

Beauvois, M.H. (1994). E-talk: Attitudes and motivation in computer-assisted classroom discussion. Computers and the Humanities, 28(3), 177-190.

Blasszauer, J . (2001). Collaborative projects via the internet. Teaching English With Technology: A J ournal for Teachers of English, 1(6), 1-7.

Braine, G., \&Yorozu, M. (1998). Local area network (LAN) computers in ESL and EFL writing classes: Promises and realities. J ALT J ournal, 20(2), 47-59.

Brandl, K. (2002). Integrating internet-based reading materials into the foreign language curriculum: From teacher-to student-centered approaches. Language Learning \& Technology, 6(3), 87-107.

Chalmers, P.A. (2003). The role of cognitive theory in human- computer interface. Computers in Human Behavior, 19(5), 593-607.

Ching, Y. H., \& Hsu, Y. C. (2013). Peer feedback to facilitate project-based learning in an online environment. The International Review of Research in Open and Distance Learning, 14(5), 258-276.

Cononelos, T., \& Oliva, M. (1993). Using computer networks to enhance foreign language/ culture education. Foreign Language Annals, 26(4), 527-534.

Cox, M., Webb, M., Abbott, C., Blakeley, B., Beauchamp, T., \& Rhodes, V. (2004). A review of the research literature relating to ICT and attainment. London: Becta.

Crystal, D. (1997 c). English as a global language. Cambridge: Cambridge University Press.

Crystal, D. (2001). Language and the internet: Cambridge University Press.

Fraenkel, J . R., Wallen, N.E., \& Hyun, H. (2011). How to design and evaluate research in education. NewYork: McGraw-Hill

Gass, S.M., \& Selinker, L. (2008). Second language acquisition: An introductory course. Routledge.

Gu, Y., \&J ohnson, R.K. (1996). Vocabulary learning strategies and language learning outcomes. Language Learning, 46(4), 643-679.

This work is licensed under a $\underline{\text { Creative Commons Attribution } 4.0 \text { International License. }}$ 
Hartman, K., Neuwirth, C.M., Kiesler, S., Sproull, L., Cochran, C., Palmquist, M., \&Zubrow, D. (1991). Patterns of social interaction and learning to write some effects of network technologies. Written Communication, 8(1), 79-113.

Hellebrandt, J . (1999). Virtual collaborations in the Spanish class: From e-mail to web design and CD-ROM development. J ournal of Educational Computing Research, 20(1), 59-70.

Hertel, T.J . (2003). Using an e-mail exchange to promote cultural learning. Foreign Language Annals, 36(3), 386-396.

Honeyfield, J . (1977). Word frequency and the importance of context in vocabulary learning. RELCJ ournal, 8(2), 35-42.

Hult, S., Kalaja, M., Lassila, O., \&Lehtisalo, T. (1990). Hyperreader-an interactive course in reading comprehension. System, 18(2), 189-198.

J ogan, M.K., Ana, H.H., \& Gladys, A.M. (2001). Cross-cultural e-mail: Providing cultural input for the advanced foreign language student. Foreign Language Annals, 34(4), 341-346.

J owallah, R. (2014). An investigation into the management of online teaching and learning spaces: A case study involving graduate research students. The International Review of Research in Open and Distance Learning, 15(4), 186-198.

Kost, C.R. (1999). Enhancing communicative language skills through effective use of the world wide web in the foreign language classroom. Foreign Language Annals, 32(3), 309-320.

Kroonenberg, N. (1994). Developing communicative and thinking skills via electronic mail. TESOLJ ournal, 4(2), 24-27.

LeLoup, J .W. (1997). But I only have e-mail--what can I do? Learning Languages, 2(2), 10-15.

Liu, M. (1995). Hypermedia assisted instruction and second language learning: A semanticnetwork-based approach. Computers in the Schools, 10(3-4), 293-312.

Lunde, K.R. (1990). Using electronic mail as a medium for foreign language study and instruction. Calico J ournal, 7(3), 68-78.

Mahmoudi, E., \& Razak, N.Z.B.A. (2012). Attitude and students' performance in computer assisted English language learning (CAELL) for learning vocabulary. Procedia-Social and Behavioral Sciences, 66, 489-498.

Matthiesen, S., J . (2007). Barron's essential words for the TOEFL. Barron's Educational Series: New York. 
Meara, P. (1980). Vocabulary acquisition: A neglected aspect of language learning. Language Teaching and Linguistics: Abstracts, 13(4), 221-246.

Meishar-Tal, H., Kurtz, G., \& Pieterse, E. (2012). Facebook groups as LMS: A case study. The International Review of Research in Open and Distance Learning, 13(4), 33-48.

Meskill, C., \&Anthony, N. (2005). Foreign language learning with CMC: Forms of online instructional discourse in a hybrid Russian class. System, 33(1), 89-105.

Mike, D.G. (1996). Internet in the schools: A literacy perspective. J ournal of Adolescent \& Adult Literacy, 40(1), 4-13.

Morgan, J., Rinvolucri, M., \& Maley, A. (1986). Vocabulary. Oxford University Press.

Mustafa, H.R., Sain, N., \& Razak, N.Z.A. (2012). Using internet for learning vocabulary among second language learners in a suburban school. Procedia-Social and Behavioral Sciences, 66, 425-431.

Najafi, H., Evans, R., \& Federico, C. (2014). MOOC integration into secondary school courses. The International Review of Research in Open and Distance Learning, 15(5), 306-322.

Naraghizadeh, M., \& Barimani, S. (2013). The effect of CALL on the vocabulary learning of Iranian EFL learners. J ournal of Academic and Applied Studies, 3(8), 1-12.

Nation, P., \& Beglar, D. (2007). A vocabulary size test. Retrieved from http:// www.lextutor.ca/

Schreurs, B., Van den Beemt, A., Prinsen, F., Witthaus, G., Conole, G., \& De Laat, M. (2014). An investigation into social learning activities by practitioners in open educational practices. The International Review of Research in Open and Distance Learning, 15(4), 1-20.

Agca, R. K., \&Özdemir, S. (2013). Foreign language vocabulary learning with mobile technologies. Procedia-Social and Behavioral Sciences, 83, 781-785.

Segers, E., \&Verhoeven, L. (2009). Learning in a sheltered internet environment: The use of webquests. Learning and Instruction, 19(5), 423-432.

Shams, I.E. (2013). Hybrid learning and Iranian EFL learners' autonomy in vocabulary learning. Procedia-Social and Behavioral Sciences, 93, 1587-1592.

Singhal, M. (1997). The internet and foreign language education: Benefits and challenges. The Internet TESL J ournal, 3(6), 107.

This work is licensed under a Creative Commons Attribution 4.0 International License. 
Somekh, B., Lewin, C., Mavers, D., Fisher, T., Harrison, C., Haw, K., . . Scrimshaw, P. (2002). Impact2: Pupils' and teachers' perceptions of ICT in the home, school and community. British Educational Communications and Technology Agency (BECTA).

Turgut, Y., \& Irgin, P. (2009). Young learners' language learning via computer games. ProcediaSocial and Behavioral Sciences, 1(1), 760-764.

Velasquez, A., Graham, C. R., \&West, R. E. (2013). An investigation of practices and tools that enabled technology-mediated caring in an online high school. The International Review of Research in Open and Distance Learning, 14(5), 277-299.

Warschauer, M. (1995). Virtual connections: Online activities and projects for networking language learners: Natl Foreign Lg Resource Ctr.

Weininger, M.J ., \& Shield, L. (2003). Promoting oral production in a written channel: An investigation of learner language in MOO. Computer Assisted Language Learning, 16(4), 329-349.

Yang, S.C. (2001). Language learning on the world wide web: An investigation of EFL learners' attitudes and perceptions. J ournal of Educational Computing Research, 24(2), 155-182.

Yang, S.C., \& Chen, Y.-J . (2007). Technology-enhanced language learning: A case study. Computers in Human Behavior, 23(1), 860-879.

Zarei, G. R., \& Khazaie, S. (2011). L2 vocabulary learning through multimodal representations. Procedia-Social and Behavioral Sciences, 15, 369-375.

(C) Ahangar and Izadi

\section{Athabasca University}

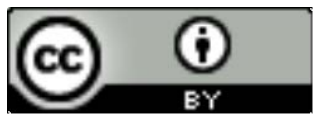

